\title{
Application of Information Engineering in Hospital Management
}

\author{
Na Wang ${ }^{1}$ and Jinguo Wang ${ }^{2, a, *}$ \\ ${ }^{1}$ Department of Anesthesiology, First Hospital of Jilin University, Changchun, China \\ ${ }^{2}$ Department of Urology, First Hospital of Jilin University, Changchun, China \\ ${ }^{*}$ Corresponding author: Jinguo Wang
}

\begin{abstract}
In order to realize cross-hospital data sharing and solve the problem of system interconnection, an information service platform was set up to build homogeneity of the core system, unify the basic standard, and recreate the business process, so as to achieve integration of multiple hospital systems. The system integration of this information service platform realizes the interconnection and interworking of the systems of the two chambers. It facilitates the inter-hospital inspection appointment, bed appointment and inter-hospital transfer of patients, with strong scalability. This platform and technology application which has realized the system connectivity is reasonable. The hospitals of the same patient can share the medical information, improve the utilization rate of health resources and the patient's clinic experience. It can further improve the utilization rate of hospital beds and efficiency of clinical work. The unification data for fine management advancement will also provide more data to support.
\end{abstract}

\section{Introduction}

At present, there is no unified or guiding standard for the information system hospital administrative management, and the management mode among hospitals is not the same. It can't fully meet the needs of developing and maintaining the system relying solely on outsourcing software companies [1]. Therefore, the hospital needs to strengthen the construction of professional information technology team, cultivate a modern information awareness, proficient in computer and medical and management knowledge, to meet the needs of various information management talent team, so as to realize the hospital information service.

Electronic information engineering mainly relies on the network as the carrier. Although it can be prevented and protected by the method of network firewall and the separation of internal and external networks, there are still threats such as information leakage and deliberate attack. In particular, the information in the hospital system involving patient privacy should be kept strictly confidential, once it is leaked, it will cause great impact. Information may also be accessed, modified, or copied illegally due to incorrect user permissions. Information management also has problems such as data loss and wrong deletion due to improper operation. Data recovery and backup are great challenges for managers who are not familiar with computer operation [2].

\section{Advantages}

\subsection{Improving work efficiency}

a Corresponding author: wangjinguolily@163.com
Application of electronic information engineering in the hospital administration can be used to intelligent information technology to the hospital operation of all kinds of information resources integration and processing, for the most part to reduce the expense of human resources, electronic information engineering can link the hospital each department as an information network, thus the high-speed transmission of information, improve the administrative efficiency [3]. At the same time, the application of electronic information engineering can reduce human error, through the application of electronic information engineering management process can be more standardization, standardization, all kinds of information resources in the process of transmission distortion less likely, and application of information technology on data processing can guarantee the result more accurate, provide the decision-making basis for the management.

\subsection{Promoting a scientific and standardized hospital management}

In the traditional hospital management model will inevitably be some bugs, management oversight, responsibility is unknown, so through the electronic information engineering can help hospital administration form a complete set of management system, from the Angle of scientific, standardized, to control the administrative work, strengthen the administrative management implementation degree of transparency, can make it in the system under the supervision of executive management function [4]. And in the application of electronic information engineering can set user rights, 
operation rights. Restrictions to avoid non-administrative staff of illegal operations should be established.

\section{Problems in the application of information engineering in hospital administration}

The application of electronic information engineering in the field of hospital has just started and developed in recent years, so it is inevitable to have some application problems in the actual system. In addition, affected by the characteristics of hospital, there is still a certain gap between the actual effect and the ideal effect in the application of electronic information engineering in the administrative management. With the penetration of high technology into medicine, the rapid development of medicine has been promoted [5]. Strengthening the training of medical information talents is the key link and centennial plan to revitalize and develop China's medical and health undertakings [6]. Medical information personnel is the exclusive grasp of modern information technology talented person, the rapid development of science and technology and the resulting surge in total of knowledge, knowledge update faster, at the same time, the development of information technology and widely used in the medical field, requires our country to cultivate professional information talents with comprehensive quality, with solid basic knowledge of natural science and humanities, mastering discipline basic theory and basic knowledge, to master the basic theory of medical information science and information technology and technical skills. Ability of analysis, research, development and utilization and effective management of medical information resources is necessary for doctors [7].

\section{Solutions}

\subsection{Paying attention to information engineering technicians}

In recent years, with the improvement of informatization, the status of medical information engineering technicians has increased, but they pay more attention to clinical front-line staff objectively [8]. Therefore, from the perspective of information technology personnel, on the one hand, they should actively strengthen communication with the leadership of the hospital to promote the change of their thinking ideas $[9,10]$. On the other hand the overall demand in the management of hospital information, from the construction of the information network, business planning, design method and the reconfiguration of the information equipment, combined with the development of the hospital status and financial situation, put forward the feasible implementing scheme, for the hospital leaders to develop hospital informationization development planning advice, provide strong support for the leadership decision-making [11]

\subsection{Optimizing the structure of information engineering technicians}

In view of the decrease in the proportion of military cadres, the increase of non-active civilian staff and contract staff, the number of junior and senior titles, and the small number of intermediate titles, the concept of relying solely on military cadres should be broken down, and the cultivation of young and middle-aged cadres with different components should be actively strengthened [12]. Through the preferential policies of on-the-job training, appraisal and award, young backbones are encouraged to continuously improve their professional quality and skills, and obtain the corresponding professional and technical qualifications. We will make use of the military's civilian personnel policy to attract highly qualified and highly educated personnel from the society to be used by the armed forces and improve the gradient of troop construction [13]. At the same time, the system of rotating posts should be implemented to strengthen the training of new technical personnel, expand the knowledge and skills of medical information engineering technical personnel, so as to make them competent for various jobs and at the same time improve the work challenges. Stimulate their enthusiasm to research and explore business work, and improve their business level and research ability. However, due to the complexity, diversity and professionalism of the hospital information system, the backbone of each group should be kept relatively in the job rotation, so it is not suitable to rotate all posts, and the rotation training is too frequent

\section{Conclusion}

In recent years, with the development of medical big data, the knowledge and data in the medical field also increase dramatically, and the types of data gradually increase. Images, texts, waveforms, genetic data and structured data in electronic medical records are increasingly available. Complexity of the system increases gradually, the system standard is various, the interface type is not consistent. It is information management or application development. The difficulty is deepening day by day. Therefore, the booming development of medical information field has an increasingly urgent demand for medical information talents.

\section{References}

1. Shannon Williams. Information Literacy Instruction for Educators: Professional Knowledge for an Information Age. Library Journal, 2004.

2. Marlene Asselin. Improving literacy education through professional study: The leadership role of the teacher-librarian. Teacher Librarian, 2003.

3. Powell Carol A, Case-Smith Jane. Information literacy skills of occupational therapy graduates: a survey of learning outcomes. Journal of the Medical Library Association: JMLA, 2003. 
4. Behrens Shirley J. A conceptual analysis and historical overview of information literacy. College and Research Libraries, 1994.

5. Shannon Williams. Information Literacy Instruction for Educators: Professional Knowledge for an Information Age. Library Journal, 2004.

6. Information Literacy Initiative. SUNY Council of Library Directors. http://www.sunyconnect.suny.edu/ ili/final.htm, 2011.

7. Stanford's Key to Information Literacy. The Board of Trustees of the Leland Stanford Junior University. http://skil.stanford.edu/intro/index.html, 2011.

8. Marlene Asselin. Improving literacy education through professional study: the leadership role of the teacher-librarian. Teacher Librarian, 2003.
9. Loanne Snavely. Making Problem-Based Learning Work: Institutional Changes. Portal: Libraries and the Academy, 2004 (4).

10. Janis F. Brown, Janet L. Nelson. Integration of Information Literacy into a Revised Medical School Curriculum. Medical Reference Services Quarterly, 2003 (3).

11. Doyle C. Outcome measures for information literacy within the national education goals of 1990. http://www.infolit.org./index.html, 1992.

12. The Prague Declaration "Towards an Information Literate Society". UNESCO. http://portal.unesco.org/ ci/en/ev.php-URL_ID=19636\&.URL_DO=DO_TOP IC\&.URL SECTION=201.html, 2011.

13. Luigi T. De Luca, Les Ulis. Propulsion physics. EDP Sciences, 2009. 